\title{
Nilai Tahanan Kontak Pada Pms Bay Cengkareng Terhadap Rugi Daya Di Gardu Induk Duri Kosambi
}

\author{
Novi Gusti Pahiyanti'; Sigit Sukmajati²; Abdul Malik ${ }^{3}$ \\ 1,2,3 Institut Teknologi PLN (Fakultas Ketenegalistrikan dan Energi Terbarukan) \\ ${ }^{1}$ novi.gusti@itpln.ac.id
}

\begin{abstract}
The powerplant is a source of electrical energy that will be distributed to the substation which will then be distrbuted back to consumers. Disconnecting switch is the equipment at the substation which supports the performance of the equipment. Maintenance on the disconnecting switch should be maintained on a regular basis which consists of cleaning and testing. One of the tests is contact resistance. This test is carried out to determine the resistance value of the disconnecting switch contact according to the standard. The difference in contact resistance values affects the resulting power loss. The greater the value of the contact resistance, the greater the value of the resulting power loss. This study was conducted to determine the value of contact resistance against power loss by comparing the value of contact resistance in 2020 and 2021. The power loss obtained is relatively small, namely the highest power loss is in the 2021 phase $R$, which is 6.417 Watt or $0.006417 \mathrm{~kW}$. Meanwhile, the lowest power loss is in phase $T$ in 2020, which is 2.603 Watt or $0.002603 \mathrm{~kW}$..
\end{abstract}

Keywords: Substation, Disconecting Switch, Resistance Contact

\begin{abstract}
ABSTRAK
Pembangkit merupakan sumber energi listrik yang akan disalurkan ke Gardu Induk yang kemudian akan disalurkan kembali kepada konsumen. Pemisah merupakan peralatan di Gardu Induk yang merupakan penunjang kinerja pada peralatan. Pemeliharaan pada pemisah sebaiknya dipelihara secara berkala yaitu terdiri dari pembersihan dan pengujian. Salah satu pengujiannya yaitu tahanan kontak. Pengujian ini dilaksanakan untuk mengetahui nilai resistansi pada kontak Pemisah sesuai dengan standarnya. Perbedaan milai tahanan kontak tersebut mempengaruhi nilai rugi daya yang dihasilkan. Semakin besar nilai tahanan kontaknya, maka semakin besar pula nilai rugi daya yang dihasilkan. Penelitian ini dilakukan untuk mengetahui nilai tahanan kontak terhadap rugi daya dengan cara membandingkan nilai tahanan kontak pada tahun 2020 dan tahun 2021. Rugi daya didapat relative kecil yaitu daya rugi daya paling tinggi terdapat pada tahun 2021 fasa $R$ yaitu 6,417 Watt atau 0,006417 kW. Sedangkan untuk rugi daya paling rendah yaitu pada fasa $T$ tahun 2020 yaitu 2,603 Watt atau 0,002603 kW.
\end{abstract}

Kata kunci: Gardu Induk, Pemisah, Tahanan Kontak 


\section{PENDAHULUAN}

Adapun Energi listrik merupakan energi yang digunakan oleh masyarakat. Energi tersebut dimana sering kali digunakan/konsumsi melihat dari perkembangan zaman yang semakin modern, hal itulah yang membuat energi listrik menjadi kebutuhan utama/pokok dalam kehidupan sehari-hari, pembangkit akan memberikan energi listrik kemudian dari pembangkit ini kemudian ditransmisikan pada jaringan distribusi yang di mana pada jaringan distribusi akan diberikan ke tegangan yang lebuh rendah yaitu merupakan pemanfaatan energi listrik ataupun pada konsumen, pada gardu induk sendiri terdapat terdapat beberapa peralatan untuk menunjang penyaluran energi listrik yang terbagi menjadi beberapa jenis dan pada setiap peralatan memiliki karakteristik yang berbeda-beda juga, pada peralatan yang ada di gardu induk tersebut juga perlu adanya pemeriksaan rutin aupun pemeliharaan untuk beberapa peralatan yang ada pada gardu induk mudah mengalami kerusakan, hal tersebutlah yang melatarbelakangi perlunya pemeliharaan pada perlengkapan gardu tersebut.

Pemisah merupakan salah satu perlengkapan pada gardu induk gardu induk dari perlengkapan lain yang bertegangan, pada pengoperasian pembukaan ataupun penutupan pada pemisah/disconnecting switch ini dilakukan saat tidak berbeban. pemisah/disconnecting switch dipasang diantara pemutus tenaga dengan sumber energi listrik, Setelah pemutus tenaga juga dipasang pemisah line dan juga pemisah tanah, yang dimana pada pemisah line ini sendiri telah dilengkapi dengan pengaman interlock, yang apabila pada pemisah pemisah line belum dalam kondisi open makan pemisah tanahnya tidak akan dapat dimasukkan. (28)

Pada penelitian dilaksanakan agar penulis dapat mengetahui nilai yang harusnya terukur pada nilai tahanan kontak pada pemisah/disconnecting switch (PMS) dan pada nilai tersebutlah yang dapat dugunakan untuk menghitung berapa besar kerugian pada penyulang tersebut dan pengukuran/pengujian ini berfungsi untukmelakuakan upaya apa yang perludilakukan dan hasil pengukuran/pengujian dapat ditinjau ada tidaknya masalah.

\section{METODE/PERANCANGAN PENELITIAN}

Kegiatan penelitian berikut akan dilakukan Studi Pustaka, melakukan studi analisis data kebutuhan peralatan yang akan digunakan. Studi lapangan, melakukan studi lapangan dengan mencoba selama 4 bulan. Pengumpulan informasi yang diperlukan dalam penelitian ini besarnya nilai tahanan kontak serta arus. Dengan pemilihan yang pilih untuk yang di inginkan sesuai dengan diagram alir.

Rugi daya disini terjadi dikarenakan nilai pada tahanan kontak yang yang terukur besar, pada suatu rangkaian pasti ada yang disebut dengan titik sambungan yang minimal adalah pertemuan dari dua buah permukaan pada suatu kawat konduktor, sambungan dari pertemuan konduktor ini pasti akan menimbulkan nilai tahanan kontak yang akan menjadi panas dapat menimbukan suatu energi panas dan hal tersebut merupakan kerugian teknis.

Kerugian tersebut merupakan kerugian yang sangat berdampak pada PLN karena apabila pada nilai tahanan kontak yang terukur tersebut nilainya besar pada sambungan antara pemisah, maka akan dapat menimbulkan tahanan kontak, yang dimana pada tahanan kontak ini pada tahanannya memenuhi kaidah Hukum Ohm sebagai berikut : 
$E=I \times R$

Dimana diketahui bahwa E merupakan tegangan dengan satuan Volt, I merupakan arus dengan satuan Amper, $\mathrm{R}$ merupakan adalah nilai tahanan dengan satuan Ohm.

Jika didapat kondisi tahanan kontak sebesar $1 \mathrm{Ohm}$ dan arus yang mengalir adalah 100 Amper maka rugi-rugi nya adalah :

$P_{\text {loss }}=I^{2} \times R$

Dimana diketahui bahwa $P_{\text {loss }}$ sebesar $10.000 \mathrm{~W}$, dengan $P_{\text {loss }}$ merupakan rugi daya dengan satuan $\mathrm{kW}, \mathrm{I}^{2}$ merupakan arus dengan satuan Amper, $\mathrm{R}$ merupakan tahanan dengan satuan Ohm.

Yang dibahas pada penelitian ini adalah susut tenaga, susut tenaga ialah jumlah tenaga $\mathrm{kWh}$ yang sirna maupun menyusut terjalin karena sebab- karena tata cara maupun non tata cara pada waktu penyediaan dan penyaluran tenaga. Kebalikannya Tenaga didefinisikan sebagai tenaga maupun kekuatan yang diperlukan buat melakukan berbagai proses kegiatan (untuk KBBI). Dimana tenaga listrik yang sirna dapat dihitung dengan mengenakan rumus:

$\mathrm{W}_{\text {loss }}=\mathrm{P}_{\text {loss }} \mathrm{xt}$

Dimana Wloss merupakan Energi listrik yang hilang dengan satuan kWh, Ploss merupakan rugi daya dengan satuan $\mathrm{kw}$, t merupakan waktu dengan satuan jam.

Berdasarkan Standing Operational Prosedur PT. PLN (Persero) dalam melakukan pembersihan pemisah ada beberapa hal yang harus dikerjakan terlebih dahulu yaitu mempersiapkan alat ukur dan asesoris lainnya serta yakinkan semuanya dalam kondisi baik, mempersiapkan toolkit yang akan digunakan, mepersiapkan blanko pengukuran, lakukan pencatatan spesifikasi PMS/ DS yang akan dikur, lalu lepaskan konduktor/ kabel atau pasang grounding pada terminal PMS/DS yang akan diukur serta diberi tanda (tagging) pada konduktor / kabel yang akan dilepas, lalu pastikan PMS/ DS dalam keadaan close / tertutup, kemudian letakkan alat ukur di tempat yang aman dan terjangkau, hal tersebut terdapat pada flowchart dibawah ini. 


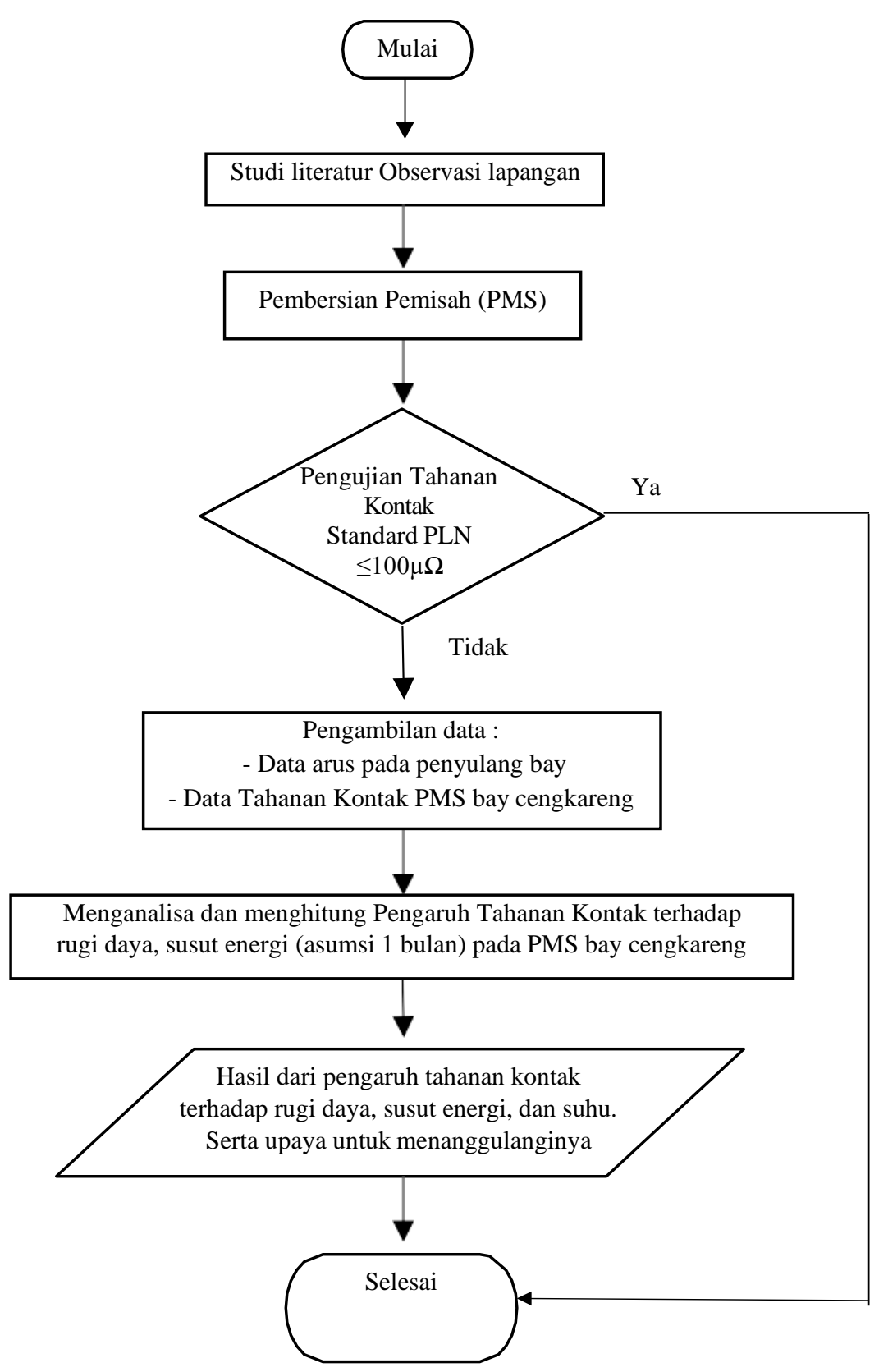

Gambar 1. Diagram Alir

Berdasarkan diagram alir diatas hal yang dilakukan yaitu melakukan wawancara atau interview terhadap staf - staf atau pegawai dari perusahaan PT. PLN (Persero) yang pekerjaanya terkait dalam hal penelitian ini, lalu melaksanakan penelitian literatu.

Pada penelitian ini terdiri dari beberapa kegiatan yang dilakukan seperti menyiapkan bahan penelitian yang akan dipakai seperti peralatan yang digunakan untuk melakukan penelitian ini seperti halnya yaitu pengukuran tahanan kontak dengan menggunakan insulation tester.

Metode kerja pada penelitian ini sangat dibutuhkan sekali dengan cara metode kuantitatif dengan mengumpulkan hasil dari pengukuran dan angka - angka yang terdapat pada tabel 1 sampai dengan tabel 4 . 
Analisis data pada penelitian ini dilakukan untuk mendapatkan hasil yang terbaik berdasarkan data salama 4 bulan, sehingga menghasilkan informasi yang diperlukan seperti halnya nilai arus pada tahanan kontak tersebut, serta tegangan pada tahanan kontak tersebut. Semua itu akan dilakukan perhitungan yang pada akhirnya memperoleh besarnya nilai rugi - rugi daya serta loses.

Dari perhitungan tersebut hendak dikenal akibat dari besarnya nilai tahanan kontak serta pula kita hendak mengenali penanganan apa yang harus segera dilakukan.

\section{HASIL DAN PEMBAHASAN}

Pada penelitian kali ini, dilakukan penelitian pada bay penghantar cengkareng, yang dimana pada bay penghantar cengkareng sendiri telah dilakukan pemeliharaan pada tahun 2020, tetapi pada tahun 2021 ditemukan adanya hotspot pada bay penghantar cengkareng pada saat dilakukan thermovisi, pada saat dilakukan thermovisi, untuk penelitian ini, akan digunakan data data yang meliputi beban pada bay penghantar cengkareng 1, bay penghantar cengkareng 2, kwh meter yang tercatat pada bay penghantar cengkareng 1 dan bay penghantar cengkareng 2 .
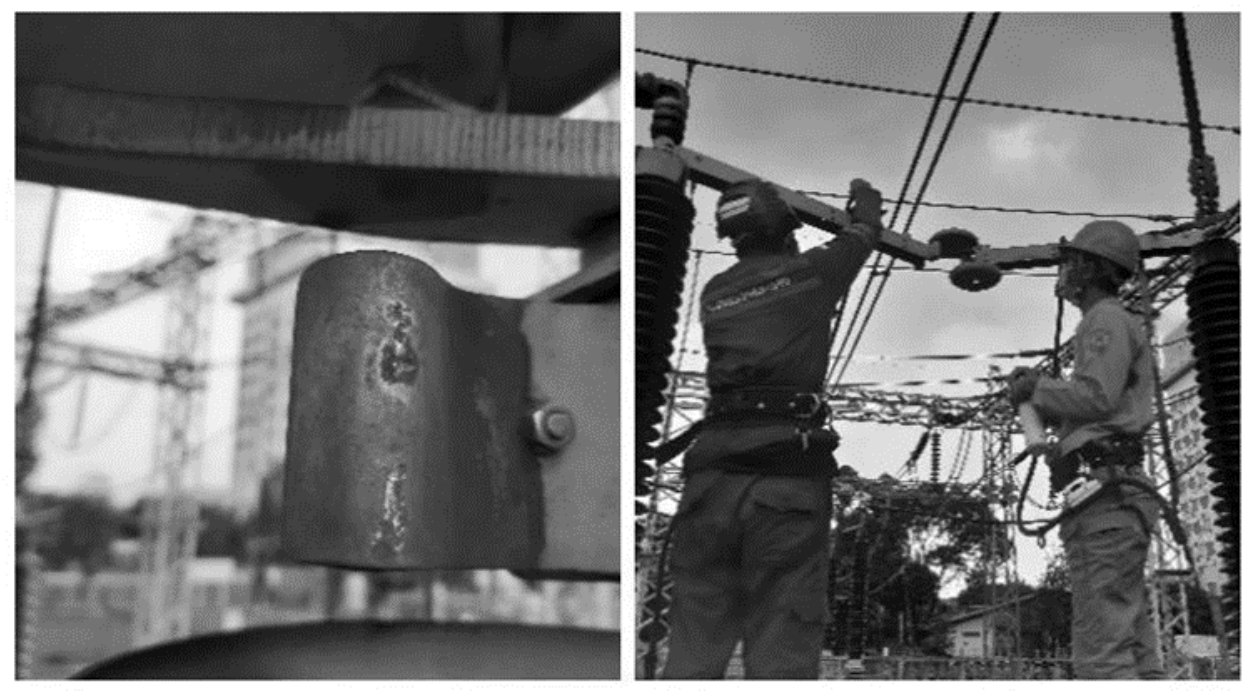

Gambar 2. Perbaikan Pemisah Akibat Hotspot

Tahanan kontak merupakan suatu nilai resistansi yang dimiliki oleh suatu pemisah atau disconecting switch. Setiap pemisah atau disconecting switch memiliki tahanan kontak yang berbeda-beda pada setiap fasanya.

Karena yang akan dibahas rugi daya tahanan kontak pada pemisah atau disconecting switch, maka dari itu, diperlukan data pengukuran tahanan kontak pada pemisah atau disconecting switch pemeliharaan tahun 2020 dan pemeliharaan tahun 2021. Hal ini dilakukan agar dapat dibandingkan rugi daya pada bay penghantar Cengkareng 1 dengan nilai pada tahanan kontak yang tahun lalu dengan tahun sekarang.

Perhitungan rugi daya dapat dirumuskan dengan mengalikan arus yang dikuadratkan dengan resistansi / tahanan kontak. Rugi daya dapat dihitung dengan menggunakan rumus (2).

Pada data arus yang diambil untuk dilakukan penelitian, diambil dari pencatatan beban yang dilakukan oleh operator gardu induk pada saat sesudah dilakukan 
pemeliharaan, pemeliharaan pada tahun 2020 dilaksanakan pada bulan Maret, dan pada pemeliharaan tahun 2020 dilaksanakan pada bulan februari. Data dapat dilihat pada tabel1.

Tabel 1. Data Pencatatan Beban Bay Penghantar Cengkareng 1 Tahun 2020

\begin{tabular}{|c|c|c|c|c|}
\hline \multicolumn{5}{|c|}{ Cengkareng 1 } \\
\hline Fasa & $k V$ & MW & Mvar & Amp \\
\hline $\mathrm{R}$ & 150 & 118 & 24 & 460 \\
\hline $\mathrm{S}$ & 151 & 127 & 10 & 489 \\
\hline $\mathrm{T}$ & 152 & 90 & 9 & 344 \\
\hline
\end{tabular}

Berdasarkan Tabel 1 diatas didapat hasil pencatatan beban bay penghantar Cengkareng 1 pada Tahun 2020 yang dilakuakan pengukuran berdasarkan tiap fasa dimulai dari fasa $\mathrm{R}, \mathrm{S}$, dan T memiliki daya sebesar masing - masing $118 \mathrm{MW}, 127 \mathrm{MW}$, dan $90 \mathrm{MW}$, sehingga menghasilkan arus tiap fasa yang berbeda pula yaitu untuk arus tiap fasa nya sebesar 460 Ampere, 489 Ampere, dan 344 Ampere. Dari hal tersebut diatas semakin besar nilai tahanan kontaknya semakin besar nilai rugi - rugi daya yang dihasilkan.

Dari data diatas dapat dihasilkan dengan menggunakan rumus 2 untuk menghitung rugi rugi daya setiap fasa didapat hasil pada tabel 2 dibawah sebagai berikut:

Tabel 2. Rugi - Rugi Daya Setiap Fasa Penghantar Cengkareng 1 Tahun 2020

\begin{tabular}{|c|c|c|c|}
\hline Fasa & $\begin{array}{c}\text { Arus } \\
\text { (Amp) }\end{array}$ & $\begin{array}{c}\text { Tahanan } \\
\text { (Mikro Ohm) }\end{array}$ & $\begin{array}{r}\text { Ploss } \\
\text { (KWatt) }\end{array}$ \\
\hline $\mathrm{R}$ & 460 & 18 & 0,003809 \\
\hline $\mathrm{S}$ & 489 & 19 & 0.004543 \\
\hline $\mathrm{T}$ & 344 & 22 & 0,002603 \\
\hline
\end{tabular}

Dibawah ini merupakan data pencatatan beban bay penghantar Cengkareng 1 yang didapat melalui hasil pengukuran. Dari hasil perhitungan rugi daya dapat dilihat bahwa setiap Pemisah atau disconecting switch memiliki tahanan kontak yang berbeda. Perbedaan tersebut mempengaruhi nilai rugi daya yang dihasilkan.

Berikut data terlampir pada Tabel 3. yaitu data pencatatan beban Bay Pengahantar I pada tahun 2021 yang telah dilakukan pengukuran. 
Tabel 3. Data Pencatatan Beban Bay Penghantar Cengkareng 12021

\begin{tabular}{|c|c|c|c|c|}
\hline \multicolumn{5}{|c|}{$\begin{array}{c}\text { Cengkareng } \\
1\end{array}$} \\
\hline Fasa & kV & MW & Mvar & Amp \\
\hline R & 151 & 119 & 21 & 468 \\
\hline S & 151 & 127 & 16 & 489 \\
\hline T & 152 & 89 & 13 & 344 \\
\hline
\end{tabular}

Berdasarkan data dari Tabel 3, maka didapat daya pada tiap fasa dimulai dari fasa R, S, sampai fasa T didapat daya sebesar 119 MW, $127 \mathrm{MW}, 89 \mathrm{MW}$ didapat arus sebesar 468 Ampere, 489 Ampere, dan 344 Ampere.

Dari hasil rugi - rugi daya setiap fasa diatas dengan menggunakan rumus 2 didapat nilai rugi - rugi daya yang terdapat pada penghantar Cengkareng 1 tahun 2021. Berikut data terlampir pada tabel 4 .

Tabel 4. Rugi - Rugi Daya Setiap Fasa Penghantar Cengkareng 1 Tahun 2021

\begin{tabular}{|c|c|c|c|}
\hline Fasa & $\begin{array}{c}\text { Arus } \\
\text { (Amp) }\end{array}$ & $\begin{array}{c}\text { Tahanan } \\
\text { (Mikro Ohm) }\end{array}$ & $\begin{array}{r}\text { Ploss } \\
\text { (KWatt) }\end{array}$ \\
\hline R & 468 & 29,3 & 0,006417 \\
\hline S & 489 & 30,0 & 0,00744 \\
\hline T & 344 & 32,6 & 0,003858 \\
\hline
\end{tabular}

Dari tabel diatas didapat bahwa setiap Pemisah atau disconecting switch memiliki tahanan kontak yang berbeda. Perbedaan tersebut mempengaruhi nilai rugi daya yang dihasilkan. Semakin besar nilai tahanan kontaknya, maka semakin besar pula nilai rugi daya yang dihasilkan. Arus yang mengalir juga berpengaruh pada nilai rugi daya, karena rugi daya itu kuadrat arus dikali tahanan kontak, dimana semakin besar arus yang mengalir, maka semakin besar pula rugi dayanya.

Setelah itu kan dilakukan perhitungan susut energi dengan menggunakan rumus 3 dimana dilakukan dari tahun 2020 dan tahun 2021 yang dapat dilihat pada Tabel 5 dibawah ini.

Tabel 5. Perhitungan Susut Energi Pada Tahun 2020 dan Tahun 2021

\begin{tabular}{|c|c|c|}
\hline Fasa & $\begin{array}{c}\text { Susut Tahun 2020 } \\
(\mathrm{kW})\end{array}$ & $\begin{array}{c}\text { Susut Tahun 2021 } \\
(\mathrm{kW})\end{array}$ \\
\hline $\mathrm{R}$ & 0,003809 & 0,016295 \\
\hline $\mathrm{S}$ & 0,004543 & 0,00744 \\
\hline $\mathrm{T}$ & 0,003312 & 0,005858 \\
\hline
\end{tabular}


Dari hasil perhitungan energi listrik yang hilang, dapat dilihat bahwa energi listrik yang hilang pada setiap fasa itu berbeda hasil perhitungan tersebut didapat bahwa susut pada tahun 2020 lebih kecil untuk tiap fasanya dibandingan dengan nilai susut pada tahun 2021 .

Semakin besar rugi daya, maka semakin besar pula energi listrik yang hilang. Penentuan waktu yang diasumsikan dapat memudahkan dalam perhitungan energi listrik, karena waktu pada setiap pemutus pemisah dianggap sama. Nilai tahanan kontak dapat dilihat pada Tabel 6. Dibawah ini.

Tabel 6. Nilai Tahanan Kontak

\begin{tabular}{|c|c|c|}
\hline $\begin{array}{c}\text { Nilai Tahanan } \\
\text { Kontak }\end{array}$ & $\mathrm{P}_{\text {loss }}$ & $\mathrm{W}_{\text {loss }}$ \\
\hline $100 \mu \Omega$ & $24,8 \mathrm{~W}$ & $18451,3 \mathrm{~W}$ \\
\hline $500 \mu \Omega$ & $105,8 \mathrm{~W}$ & $78715,2 \mathrm{~W}$ \\
\hline $1000 \mu \Omega$ & $219,0 \mathrm{~W}$ & $162936,0 \mathrm{~W}$ \\
\hline
\end{tabular}

Tabel 6 , diatas menjelaskan bahwa tiap nilai tahanan kontak dengan nilai $100 \mu \Omega$, $500 \mu \Omega, 1000 \mu \Omega$, didapat nilai rugi - rugi daya dan nilai susut energi yang semakin besar, hal tersebut dapat berdampak panas yang dapat menyebabkan pisau pada pemisah bisa sampai meleleh atau orang lapangan biasa menyebutnya ngelas. Semakin tinggi nilai tahanan kontaknya maka semakin tinggi juga suhu yang mengalir, sehingga Pemisah / disconecting Switch tidak dapat lagi menahan suhu sesuai kemampuannya dan terjadilah ledakan apabila sampai meleleh dan terjadi adanya GAB atau cela pada kontak pemisah, yang dimana gab tersebut timbul karena lelehan dari kontak pisau.

\section{KESIMPULAN DAN SARAN}

Hasil penelitian ini berdasarkan dengan hasil perhitungan diatas, mendapatkan hasil kesimpulan sebagai berikut:

Pengujian ini dilaksanakan untuk mengetahui nilai resistansi pada kontak Pemisah sesuai dengan standarnya. Perbedaan milai tahanan kontak tersebut mempengaruhi nilai rugi daya yang dihasilkan. Semakin besar nilai tahanan kontaknya, maka semakin besar pula nilai rugi daya yang dihasilkan. Penelitian ini dilakukan untuk mengetahui nilai tahanan kontak terhadap rugi daya dengan cara membandingkan nilai tahanan kontak pada tahun 2020 dan tahun 2021. Rugi daya didapat relative kecil yaitu daya rugi daya paling tinggi terdapat pada tahun 2021 fasa $R$ yaitu 6,417 Watt atau 0,006417 kW. Sedangkan untuk rugi daya paling rendah yaitu pada fasa T tahun 2020 yaitu 2,603 Watt atau $0,002603 \mathrm{~kW}$.

Saran untuk penelitian ini yaitu perlu melakukan pemeliharaan guna untuk memperbaiki nilai tahanan kontak dengan cara membersikan pisau pemisah dan melakukan perbaikan motor mekanik agar pisau pemisah pada PMS dapat menutup secara sempurna.

\section{UCAPAN TERIMAKASIH}

Ucapan terima kasih saya ucapkan kepada pihak terkait yang mendukung selesainya jurnal ini, terutama pada PLN Cengkareng yang telah memberikan tempat dalam penelitian ini, serta tim yang telah mendukung terselesainya Jurnal ini. 


\section{DAFTAR PUSTAKA}

[1] M. R. Maghami, H. Hizam, C. Gomes, M. A. Radzi, M. I. Rezadad, and S. Hajighorbani, "Power loss due to soiling on solar panel: A review," Renewable and Sustainable Energy Reviews. 2016.

[2] C. Hachem, P. Fazio, and A. Athienitis, "Solar optimized residential neighborhoods: Evaluation and design methodology," Sol. Energy, vol. 95, pp. 42-64, 2013.

[3] M. G. Molina, E. C. Dos Santos, and M. Pacas, "Improved power conditioning system for grid integration of photovoltaic solar energy conversion systems," 2010 IEEE/PES Transm. Distrib. Conf. Expo. Lat. Am. T D-LA 2010, pp. 163-170, 2011.

[4] a P. S. Panel and P. Affairs, "Integrating Renewable Electricity on the Grid A Report by the APS Panel on Public Affairs," Leadership, 2010.

[5] M. Benghanem, "Optimization of tilt angle for solar panel: Case study for Madinah, Saudi Arabia," Appl. Energy, 2011.

[6] T. Tudorache and L. Kreindler, "Design of a solar tracker system for PV power plants," Acta Polytech. Hungarica, 2010.

[7] S. A. Arefifar, F. Paz, and M. Ordonez, "Improving solar power PV plants using multivariate design optimization," IEEE J. Emerg. Sel. Top. Power Electron., vol. 5, no. 2, pp. 638-650, 2017.

[8] C. Y. Tang, S. Y. Ou, and Y. C. Su, "Design and implementation of a hybrid maximum power point tracker in solar power system," in Proceedings of the International Conference on Power Electronics and Drive Systems, 2011, pp. 999-1003.

[9] H. Z. Al Garni and A. Awasthi, "Solar PV Power Plants Site Selection: A Review," in Advances in Renewable Energies and Power Technologies, vol. 1, 2018, pp. 57-75.

[10] L. Miloudi, D. Acheli, and A. Chaib, "Solar tracking with photovoltaic panel," in Energy Procedia, 2013.

[11] H. Kang, T. Hong, S. Jung, and M. Lee, "Techno-economic performance analysis of the smart solar photovoltaic blinds considering the photovoltaic panel type and the solar tracking method," Energy Build., vol. 193, pp. 1-14, 2019.

[12] M. S. Hossain, N. K. Roy, and M. O. Ali, "Modeling of solar photovoltaic system using MATLAB/Simulink," in 19th International Conference on Computer and Information Technology, ICCIT 2016, 2017, pp. 128-133.

[13] T. Y. Hee and M. M. Isa, "Design of a mini solar power system," SCOReD2009 - Proc. 2009 IEEE Student Conf. Res. Dev., no. SCOReD, pp. 300-302, 2009.

[14] D. Karabetsky and V. Sineglazov, "Conceptual Design of Solar Power System," in 2018 IEEE 5th International Conference on Methods and Systems of Navigation and Motion Control, MSNMC 2018 - Proceedings, 2018, pp. 32-35.

[15] C. T. Tsai, Y. B. Muna, H. Y. Lin, C. C. Kuo, and R. Hsiung, "Optimal design and performance analysis of solar power microsystem for mini-grid application," Microsyst. Technol., 2018.

[16] K. K. McCullough, "Sustainable Residential Development: Planning and Design for Green Neighborhoods,” J. Am. Plan. Assoc., vol. 74, no. 4, pp. 526-527, 2008.

[17] T. Santala, R. Sabol, and B. G. Carbajal, "OPTIMIZED SOLAR MODULE DESIGN.," Conf Rec IEEE Photovolt. Spec Conf 13th, pp. 733-737, 1978.

[18] G. O. G. Löf and R. A. Tybout, "The design and cost of optimized systems for residential heating and cooling by solar energy," Sol. Energy, vol. 16, no. 1, pp. 9-18, 1974. 
[19] I. Indrianto, M. N. I. Susanti, R. Arianto, and R. Ruli, "Embedded System Practicum Module Design to Increase Student Comprehension of Microcontroller," TELKOMNIKA, vol. 16, no. 1, pp. 53-60, 2018.

[20] R. Ruli A. Siregar, H. Sikumbang, I. B. Sangadji, and Indrianto, "KWh Meter Smart Card Model Token For Electrical Energy Monitoring," MATEC Web Conf., vol. 218, p. 03002, 2018.

[21] I. Sangadji, Y. Arvio, and Indrianto, "Dynamic Segmentation of Behavior Patterns Based On Quantity Value Movement Using Fuzzy Subtractive Clustering Method," J. Phys. Conf. Ser., vol. 974, no. 1, 2018.

[22] S. Chanagala and Z. J. Khan, "Energy efficiency," in Studies in Computational Intelligence, 2019.

[23] G. K. Singh, "Solar power generation by PV (photovoltaic) technology: A review," Energy. 2013.

[24] S. A. Kalogirou, "Environmental benefits of domestic solar energy systems," Energy Convers. Manag., 2004.

[25] M. F. Almi, "Energy Management of Wind/Pv and Battery Hybrid System," Int. J. New Comput. Archit. their Appl., vol. 4, no. 4, pp. 30-38, 2014.

[26] V. Navasare and R. Yanamshetti, "Voltage Regulation Of Hybrid Wind-Solar Energy System," vol. 1, no. 4, pp. 243-247, 2014.

[27] S.Sukmajati, N. Gusti Pahiyanti, ABA Tangkilisan, "Perencanaan Pembangkit Listrik tenaga Surya Di Pos Pengamatan Gunung Soputan," Vol. 8, No. 2, Oktober 2019, PISSN 2089-1245, E-ISSN 2655-4925

[28] S, M. Gunawan dan J. Sentosa. 2013. Analisa Perancangan Gardu Induk Sistem Outdoor 150 kV di Tallasa, Kabupaten Takalar, Sulawesi Selatan 